\title{
The domestication of fire as a social- ecological regime shift
}

\author{
Reinette Biggs ${ }^{1,2}$, W.J. Boonstra', G. Peterson ${ }^{1}$ and M. Schlüter ${ }^{1}$
}

\begin{abstract}
Social-ecological regime shifts involve large, often abrupt, reorganizations in interlinked social and ecological systems. The domestication of fire illustrates how physiological and social changes enabled humans to start actively controlling fire, dramatically reshaping the environment and society itself.
\end{abstract}

While many changes to the environment occur gradually in response to changing conditions, some changes occur abruptly and may be difficult or impossible to reverse. Examples of such changes have been documented in terrestrial, aquatic, marine and climate science, as well as in archeology and psychology, at timescales ranging from paleo records to contemporary observations (Scheffer 2009; also see www.regimeshifts.org). In this article, we briefly introduce the notion of social-ecological regime shifts, namely abrupt shifts that involve components of both social and ecological systems.

\section{What is a social-ecological regime shift?}

There is growing interest in social-ecological regime shifts, which we define as a substantive change in the structure and function of interconnected social-ecological systems (SES). Such shifts are associated with a reconfiguration of dominant feedback processes and typically arise from a combination of gradual changes in underlying conditions and a large external shock (Biggs et al. 2012; Fig. 1). Although the shift itself may take decades or centuries, it is usually abrupt relative to the duration of each regime. Social-ecological regime shifts are important as they often have substantive impacts on the ecosystem services and benefits people obtain from SES, and often occur unexpectedly.

While studies have addressed regime shifts in ecological, and to some extent, social systems, there has been limited work on shifts in coupled SES. As with the broader emerging area of SES studies, it is still unclear how social-ecological regime shifts can be most usefully conceptualized and analyzed. Currently, the notion of social-ecological regime shifts can refer to: (1) shifts that arise from ecological dynamics (e.g. eutrophication) and consider the social and economic impacts of these changes; (2) shifts that arise from social dynamics (e.g. introduction of new legislation) and their consequent environmental effects; and (3) cases where the actual shift itself arises from the interaction of social and ecological processes (e.g. harvesting of common pool resources). The latter is perhaps most interesting as it may account for shifts that cannot arise from either social or ecological dynamics, but only occur due to the interaction of these components (Lade et al. 2013).
The concept of social-ecological regime shifts may differ somewhat from that of ecological regime shifts in terms of the type of changes it helps explain. Rather than focusing on the potential for systems to flip "back and forth" between alternate regimes (e.g. clear vs murky water lakes), it may be more useful in explaining "punctuated" change over time - i.e. periods of relatively rapid change that separate longer periods that are relatively stable, but quite different from one another in terms of SES structure and function. The inclusion of social dynamics, which enhances memory, learning, and anticipation in SES, amplifies the role of history and path dependence, reducing the reversibility of shifts. The domestication of fire illustrates this dynamic very clearly.

\section{Domestication of fire as a social- ecological regime shift}

Learning how to control fire dramatically changed how humans interacted with each other and their natural environments. Fire domestication appears to have become widespread among hominins by some 300-500 thousand years ago (Sandgathe et al. 2011). Researchers have argued that this marks the start of the

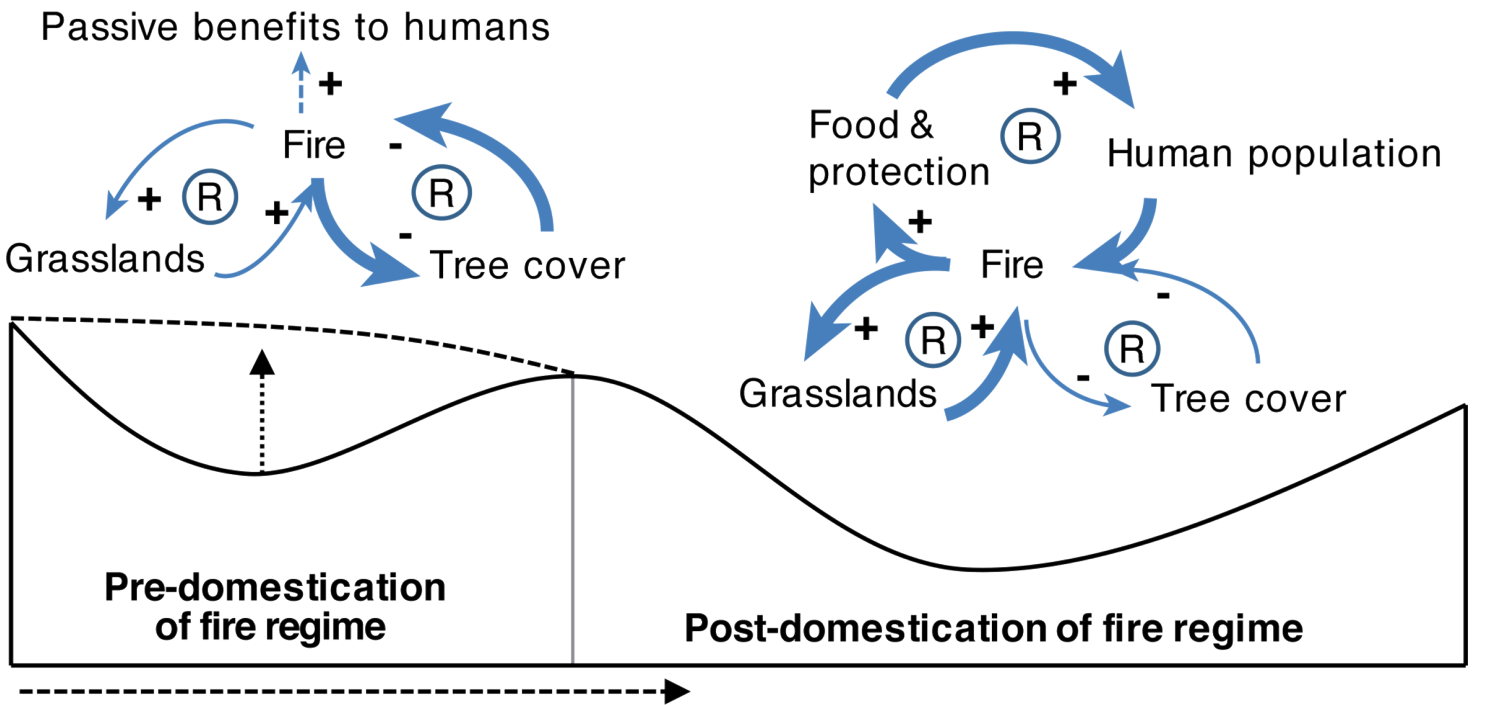

Shift triggered by slow changes in ability to walk upright, social and psychological changes 


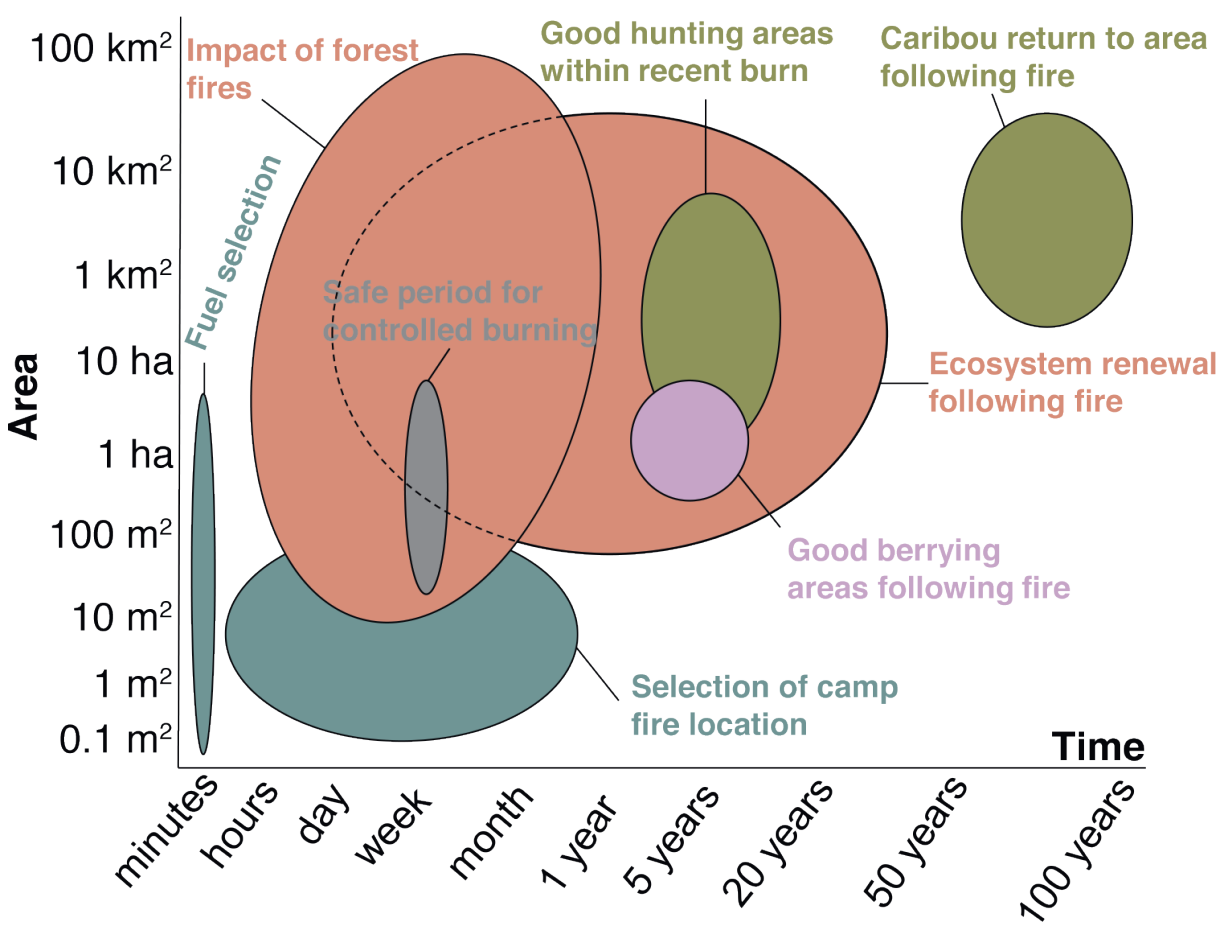

Figure 2: Spatial and temporal dimensions of knowledge related to fire use and its impacts held by Anishinaabe elders in Ontario, Canada, and the areas of expertise they require. Modified from Miller and Davidson-Hunt 2010.

Anthropocene and humanity as an Earthtransforming species (Glikson 2013).

The domestication of fire involved a shift from a long period in which hominins only passively enjoyed the benefits of fire, to a situation where they actively controlled its use (Goudsblom 2015). Researchers believe that active control of fire required physiological changes, in particular the ability to walk upright, which enabled people to use sticks to transport fire and supply it with fuel. However, social and psychological changes were also crucial: obtaining fire from wildfires, and handling and maintaining it required effort, observation, patience, anticipation and social negotiation (Twomey 2013). Before hominins could actively control fire, these social and mental skills had to become part of a learned repertoire of shared ways of thinking and doing (Goudsblom 2015; Sandgathe et al. 2011; Fig. 2).

The domestication of fire changed human demography and social interactions, and fundamentally restructured the ways in which hominins interrelated with their environments. On-site fires in hearths were used to cook food, which greatly expanded the range of foods that hominins could eat and preserve (Wrangham 2009) On-site fires also helped fend off large hominin predators such as saber-toothed cats, drive off mosquitoes and poisonous animals, harden and bend tools, and provide a source of warmth and light. They could also be used for signaling. Off-site burning in the wider landscape similarly helped hominins improve their access to food and make predators more visible. Burning of the landscape was also important for clearing vegetation, driving and attracting animals, clearing pathways, waterholes and campsites, signaling, asserting rights, warfare, ritual activities, and for aesthetic pleasure and entertainment (Scherjon et al. 2015).

Anthropogenic burning of the landscape was typically patchier, and more extensive and intensive than wildfires, and in time reshaped entire ecosystems (Bowman et al. 2011). This impact is most clearly expressed in the increasing global abundance of grasslands after the domestication of fire (Pyne 2013). Control of fire also changed the balance of power between hominins and the species they competed with for food (including other hominin groups), or that preyed on them. Anthropogenic burning of landscapes may have contributed to the mass extinction of large animals during the Pleistocene (Rule et al. 2012). The use of fire therefore radically changed the ecological niche of (early) humans (Odling-Smee et al. 2003).

This example illustrates how ecological, social and psychological changes reinforced one another to produce far-reaching changes, that not only permanently reshaped ecosystems and human society, but also the relationship between humans and nature (Fig. 1). This massive systemic reconfiguration has been argued to have set the stage for further large-scale social-ecological regime shifts. Changes involved in the domestication of fire spurred other social developments such as the creation of language, development of tools, population growth, enculturation (the learning of socially learned habits, routine and norms), and social distinction (Twomey 2013) that created the possibility for further radical innovations in time, most notably the domestication of plants and animals for agriculture (Burton 2009).

\section{Conclusion}

Social-ecological regime shifts are important from both a scientific and a policy perspective, as they provide a conceptual framework for understanding non-linear change associated with restructuring of coupled SES. Over shorter time horizons, social-ecological regime shifts often have large impacts on the functioning of ecosystems and society, and therefore on human wellbeing. Furthermore, such shifts usually occur unexpectedly and are often difficult or impossible to reverse, making them difficult for society to cope with or adapt to.

Over longer time horizons, social-ecological regime shifts may have far-reaching effects, fundamentally restructuring the relationships between people and nature and the long term trajectory of global change. The potential for such radical transformative change suggests that, in the context of the tremendous sustainability challenges society faces today, we should consider more deeply how shifts to more sustainable societies could unfold. The diverse, interconnected set of changes involved in the domestication of fire suggests that a transition to more sustainable societies is unlikely to involve only the development of new technologies and legislation that reduces environmental impacts. Instead, such technological and institutional changes are likely to fundamentally reshape both society and the environment in time, and transform the relationship between people and nature in ways that are difficult to foresee.

\section{AFFILIATIONS}

'Stockholm Resilience Centre, Stockholm University, Sweden

${ }^{2}$ Centre for Complex Systems in Transition, Stellenbosch University, South Africa

\section{CONTACT}

Reinette Biggs: oonsie.biggs@su.se

\section{REFERENCES}

Biggs R et al. (2012) In: Hastings A, Gross L (Eds) Encyclopedia of Theoretical Ecology. University of California Press, 609-617

Bowman DMJS et al. (2011) J Biogeogr 38: 2223-2236

Burton F (2009) Fire: the spark that ignited human evolution, University of New Mexico Press, 246pp

Glikson A (2013) Anthropocene 3: 89-92

Goudsblom J (2015) Fire and Civilization [In Dutch: Vuur en Beschaving], Van Oorschot, 295pp

Lade S et al. (2013) Theor Ecol 6: 359-372

Miller MA, Davidson-Hunt I (2010) Hum Ecol 38: 401-414

Odling-Smee FJ et al. (2003) Niche construction: the neglected process in evolution, Princeton University Press, 488pp

Pyne S (2013) Fire: Nature and Culture, Reaktion Books, 207pp

Rule S et al. (2012) Science 335: 1483-1486

Sandgathe DM et al. (2011) PNAS 108: E298

Scheffer M (2009) Critical transitions in nature and society, Princeton University Press, 400pp

Scherjon F et al. (2015) Curr Anthropol 56: 299-326

Twomey T (2013) Camb Archaeol J 23: 113-128

Wrangham $R$ (2009) Catching fire: how cooking made us human, Basic Books, 320 pp 